\title{
Mood response in training and rest condition in veteran endurance runners with a negative addiction to running: a pilot study
}

\author{
Respuesta al estado de ánimo, al entrenamiento y al descanso en corredores \\ veteranos con adicción negativa a la carrera \\ Pedro Ángel Latorre-Román ${ }^{1}$, Juan Antonio Párraga-Montilla ${ }^{1}$, \\ Felipe García-Pinillos ${ }^{2,3}$, Jesús Salas-Sánchez ${ }^{4}$ \\ 1 Departamento de Didáctica de la Expresión Musical, Plástica y Corporal. Universidad de Jaén. España. \\ 2 Departamento de Educación Física y Deportiva. Universidad de Granada. España. \\ 3 Departamento de Educación Física, Deportes y Recreación. Universidad de La Frontera. Temuco, Chile. \\ 4 Universidad Autónoma de Chile.
}

\section{CORRESPONDENCIA:}

Pedro Ángel Latorre Román

platorre@ujaen.es

Recepción: noviembre 2020 • Aceptación: abril 2021
CÓMO CITAR EL ARTÍCULO:

Latorre-Román, P.A., Párraga-Montilla, J.A., García-Pinillos, F., \& Salas-Sánchez, J. (2021). Mood response in training and rest condition in veteran endurance runners with a negative addiction to running: a pilot study. Cultura, Ciencia y Deporte, 16(49), 477484. http://dx.doi.org/10.12800/ccd.v16i49.1641

\section{Abstract}

To analyze how mood status of veteran endurance athletes is modified in training and resting days, according to addiction level toward endurance running. 30 veteran endurance athletes participated in this study (age $=40.53 \pm 8.20$ years). The Negative Addiction Scale (NAS) and the Profile of Mood Status (POMS) were used. Participants were classified like an addicted when obtained a score $\geq 5$ in NAS. Athletes performed the POMS in non-successive days, 4 training days and 4 resting days. The addicted athletes significantly increased $(p<.05)$ the scores in tension, depression and anger in resting days. In non-addicted group, the tension is significantly increased $(p=.015)$ in resting days, Non-addicted group showed in resting days, significant lower values $(p<.05)$ in tension, depression, fatigue and anger than addicted group. Non-addicted athletes showed an iceberg profile in training and resting days, while addicted athletes only in training days. Significant correlations $(p<.05)$ were found between NAS and tension, depression, fatigue and anger in resting days. The veteran endurance athletes with negative addiction to running modify the mood state in resting days, even when the rest is planned, and an increase in tension, depression, and anger values is produced.

Key words: anger, depression, fatigue, running.

\section{Resumen}

El objetivo de este estudio ha sido analizar la modificación del estado de ánimo en corredores veteranos los días que entrenan y descansan, en relación a su nivel de dependencia a la carrera de resistencia. Han participado 30 atletas veteranos de resistencia (edad=40.53 \pm 8.20 años). Se emplearon la Negative Addiction Scale (NAS) y el Profile of Mood Status (POMS). Los atletas se clasificaron como adictos con una puntuación $\geq 5$ en la escala NAS. Los atletas cumplimentaron el cuestionario POMS de manera no consecutiva 4 días de entrenamiento y 4 días de descanso durante un mes. Los atletas adictos experimentan un incremento significativo $(p<.05)$ de la tensión, la depresión y la cólera los días de descanso. En el grupo no adicto la tensión se incrementa de manera significativa ( $p=.015)$ en los días de descanso. En los días de descanso, el grupo no adicto muestra de manera significativa $(p<.05)$ menores valores de tensión, depresión, fatiga y cólera que el grupo adicto. Los atletas no adictos muestran un perfil iceberg los días de entrenamiento y descanso, los atletas adictos sólo los días de entrenamiento. Se observan correlaciones significativas $(p<.05)$ entre la escala NAS y la tensión, depresión, fatiga y cólera los días de descanso. Los corredores de resistencia con adicción negativa a la carrera modifican su estado de ánimo en los días que descansan, incluso estando el descanso programado, incrementando la depresión, la cólera y la tensión. 


\section{Introduction}

In the last few years, there has been an important increase in the participation of veteran runners in endurance races (Wilhelm, 2014). Running as an activity to improve health and personal performance has become increasingly widespread among the recreational population. Today, the number of participants in popular endurance races has increased, along with the number of organized running races. For instance, in the half marathon of Valencia 2020, Spain, 19,076 runners (19.51\% women) finished the race. The popular phenomenon of running is due, among other factors, to the satisfaction of physical and psychological health needs, goal achievement, tangible rewards, social influences, and easy availability (Carmack, \& Martens, 1979).

In addition, physical exercise is both physically and psychologically beneficial for health (Castillo et al., 2005; Garzón et al., 2005; Reynaga-Estrada et al., 2016). One of these benefits is related to the mood, which improves after training in both active and nonactive people (Bonet et al., 2017). However, despite these benefits, some people can train without limits, in unhealthy and compulsive degrees, to make exercise in some cases harmful (Glass et al., 2004; Hausenblas, \& Symons, 2002; Ruiz-Juan et al., 2016; Szabo, 2000) and addictive.

In the field of sports addiction, it is necessary to differentiate two concepts, on the one hand, the positive addiction that Glasser (1976) defines as physically and psychologically benign changes produced by regular physical exercise. On the other hand, the negative addiction, characterized by three fundamental consequences: (i) it is used as a technique for coping rather than seeking rewarding stimuli, (ii) is associated with the onset of withdrawal symptoms and, (iii) interferes with work and social and family responsibilities (Morgan, 1979). Another important phenomenon that characterizes addiction to physical activity is that it substitutes other types of behaviors (e.g., work, relationships with the family and children and health habits), which is why it interferes extraordinarily in the life of the addict. Therefore, dependence on sports practice can lead to a reduction in quality of life (Landolfi, 2013; Reynaga-Estrada et al., 2016; Salas et al., 2013) affecting physical health (e.g., running while injured or sick despite the medical) and psychosocial, with deterioration of social and personal life and processes of anxiety and concentration (Bamber et al., 2000; Meeusen et al., 2006).

Deprivation of physical exercise has been a strategy used for the analysis of addiction to it, thus the diagnostic criteria include the so-called withdrawal symptoms, expressed as the deterioration of mood status in the situation of interruption of physical exercise (Guszkowska, 2012). Symptoms of addiction (e.g., anxiety, restlessness, a feeling of guilt, tension and discomfort, apathy, nausea, lack of appetite, insomnia and headaches) appear in athletes within 24 to 36 hours after missing a training session planned (Aidman \& Woollard, 2003). Profile of Mood States (POMS) is commonly used to measure mental health in athletes (Rowley et al., 1995). Morgan (1980) established an iceberg-type mood profile as a characteristic of elite athletes and depicted a graph showing high vigor scores well above tension, depression, hostility, fatigue and confusion. Athletes with below-norm scores on the Tension, Depression, Confusion, Anger, and Fatigue scales, and above Force, are said to have a positive profile that graphically represents an iceberg (Rowley et al., 1995).

Various studies have examined the consequences of the deprivation of physical exercise in different groups of subjects, from students to various athletes such as cyclists, runners and swimmers, with different deprivation protocols from $24 \mathrm{~h}$ to 14 days (Berczik et al., 2014; Egorov, \& Szabo, 2013; Landolfi, 2013; Márquez, \& De la Vega, 2015; Nogueira et al., 2017; Parastatidou et al., 2014), indicating mood disorders such as increased anxiety, fatigue, depression, mental confusion, tension, reduced self-esteem and vigor. Most of these studies do not specify an essential aspect that could affect mood modification in the absence of physical exercise, such as the degree of prior dependence of the subject, an aspect that could more accurately determine the severity of symptoms and consequences of deprivation; especially in veteran athletes who could present high levels of socio-family and work responsibilities. Therefore, the objective of this study is to analyze the change in mood status in experienced veteran runners in both resting and training days, in relation to their level of dependence on endurance running.

\section{Material and methods}

\section{Participants}

Thirty subjects, 28 men and 2 women, with a mean age of $40.53 \pm 8.20$ years, voluntarily participated in this study. The athletes were recruited from different athletic clubs in Andalucía (Spain). The sample size is similar to previous studies (Hausenblas et al., 2008; Weinstein et al., 2007). All subjects filled out a prior 
consent and voluntary participation form in this study. Inclusion criteria were: (i) three or more years of experience in running; (ii) veteran athletes (> 35 years) as athletic categories of the Royal Spanish Athletics Federation; (iii) not have any cognitive disease or intellectual disability; (iv) train regularly, at least, three 3 running sessions per week (athletes who had been away from sports for more than a week for some reason were excluded from the sample). The study was carried out in compliance with the standards of the Declaration of Helsinki (version 2008) and following the guidelines of the European Community for Good Clinical Practice (111/3976/88 of July 1990), as well as the Spanish legal framework for clinical research in humans (Royal Decree 561/1993 on clinical trials) and the reference to the Declaration of Helsinki (2013). Informed consent and the study were approved by the Bioethics Committee of the University of Jaén.

\section{Materials and testing}

To analyze addiction to endurance running, the Negative Addiction Scale (NAS) was used (Hailey, \& Bailey, 1982). The instrument evaluates the psychological aspects of the negative dependence on career practice through a range of 13 items, assigning a score to each item ( 0 or 1 ); obtaining a scale of 14 points. High values are associated with higher levels of negative addiction. To define when athletes had negative symptoms of exercise addiction, a cut-off point of 5 points was used (Modolo et al., 2011), athletes with values above this score were placed in the symptoms of negative addiction. For this study, a Spanish translation of the original version of the Negative Addiction Scale (Hailey, \& Bailey, 1982) has been made. The scale has been translated using the reverse translation strategy (Hambleton, 1996). During this process, the original scale was translated into Spanish by a group of translators and, later, another group translated the scale back to the original language. The accuracy of the translation was judged according to the degree of coincidence with the original version. In this study, a Cronbach's Alpha value of 0.744 was obtained.

Mood was assessed through the POMS (McNair et al., 1971) in the 29-item version, adapted and validated in Spanish (Fuentes et al., 1995). In this version, the dimensions that make up the test are as follows: tension, anger, vigor, fatigue and depression. The scale score is between 0 to 4 points in each item. In this study, a Cronbach's Alpha value of 0.794 was obtained.

The Borg scale (1962) was used to assess the rating of perceived exertion (RPE) after training. In addition, a sociodemographic questionnaire carried out ad hoc was used, which included aspects related to age, sex, studies, marital status, occupation, years of training, if federated, duration of the sessions, number of sessions and if you had personal trainer.

\section{Procedure}

In a self-administered and individual way, the participant filled out the NAS and sociodemographic questionnaire, respecting the confidentiality of the data and clarifying the doubts that arose. Participants were instructed to fill out 8 forms on the POMS scale non-consecutively, 4 days of training and 4 days of rest within one month. In both cases, they would be filled out just before bed, at the end of the day. This procedure of analysis of the mood in the days of absence of training and rest was adjusted to the type of training that this type of athletes carry out, which, not being professional athletes, did not present rigorous training routines, so, it is difficult to know exactly training and rest days well in advance. Furthermore, unlike other training deprivation studies (Berlin et al., 2006; Conboy, 1994; Glass et al., 2004; Mondin et al., 1996) that used an acute (24h) or chronic withdrawal from training (14 days); the novel procedure of this study has been the monitoring of the state of mind for a month on days of absence and the presence of programmed training, known and freely chosen by the subject.

\section{Statistical analysis}

The analysis statistical data was performed using the statistical program SPSS., V.19 0.0 for Windows (SPSS Inc., Chicago, USA). Data are shown in descriptive statistics of mean, standard deviation and percentage. Tests of normal distribution and homogeneity (Kolmogorov-Smirnov and Levene's respectively) were conducted on all data before analysis. The Chi square test and the $\mathrm{T}$ test were used to analyze the homogeneity of groups in relation to the sociodemographic variables. The comparison between groups differentiated according to the NAS scale was performed using the U Mann -Whitney test and the Wilcoxon test to analyze the differences in each group between days of rest and training in the POMS scale. Spearman correlation was performed between the NAS scale and the dimensions of the POMS scale on training and rest days. Additionally, effect sizes for group differences were expressed as Cohen's $d$ (Cohen, 1988); effect sizes are reported as: trivial $(<0.2)$, small (0.2-0.49), medium (0.5-0.79), and large ( $\geq 0.8)$ (Cohen, 1988). The significance level was set at $\mathrm{p}<0.05$. 


\section{Results}

Table 1 shows the sociodemographic information of the athletes classified regarding to the NAS scale. Significant differences $(\mathrm{p}<.001)$ were found on the NAS scale between the group of athletes addicted to endurance running $(6.78 \pm 1.84)$ and non-addicted $(2.18 \pm 1.37)$. Between-group significant differences ( $p$ $=.001$ ) were also found in the age, with lower years old for the addicted group. No significant differences were found in the rest of the sociodemographic variables $(\mathrm{p} \geq .05)$.
Table 2 shows the results of the different dimensions of the POMS scale on days with training and without training in the athletes addicted and non-addicted to endurance running. Addicted athletes experienced a significant increase $(\mathrm{p}<.05)$ in tension, depression and anger on resting days. In the non-addicted group, the tension on resting days increased significantly ( $p$ $=.015$ ). In both groups, fatigue on resting days was significantly reduced $(\mathrm{p}<.01)$. On resting days, the non-addicted group showed significantly $(\mathrm{p}<.05)$ lower values of tension, depression, fatigue and anger than the addicted group.

Table 1. Sociodemographic variables in runners addicted and non-addicted to the endurance running.

\begin{tabular}{|c|c|c|c|c|c|}
\hline & & $\begin{array}{c}\text { Addicted } \\
n=14\end{array}$ & $\begin{array}{c}\text { Non-addicted } \\
n=16\end{array}$ & p-value & Cohen's d \\
\hline NAS scale. Mean (DT) & & $6.78(1.84)$ & $2.18(1.37)$ & $<.001$ & 2.965 \\
\hline Age (years). Mean (DT) & & $35.64(7.04)$ & $44.81(6.72)$ & .001 & 1.381 \\
\hline \multirow{4}{*}{ Educational level n (\%) } & No studies & $2(14.3)$ & $0(0.0)$ & \multirow{4}{*}{.156} & \multirow{4}{*}{$\begin{array}{l}0.212 \\
0.226 \\
0.124 \\
0,016\end{array}$} \\
\hline & Primary studies & $0(0.0)$ & $2(12.5)$ & & \\
\hline & Secondary studies & $2(14.3)$ & $5(31.3)$ & & \\
\hline & University studies & $10(71.4)$ & $9(56.2)$ & & \\
\hline \multirow{3}{*}{ Marital status n (\%) } & Single & $6(42.9)$ & $2(12.5)$ & \multirow{3}{*}{.130} & 0,135 \\
\hline & Married / in couple & $8(57.1)$ & $13(81.3)$ & & 0.072 \\
\hline & Widower & $0(0.0)$ & $1(6.2)$ & & 0,224 \\
\hline \multirow{2}{*}{ Occupation n (\%) } & Works & $9(64.3)$ & $12(75)$ & \multirow{2}{*}{.523} & 0.044 \\
\hline & Doesn't work & $5(35.7)$ & $4(25.0)$ & & 0.034 \\
\hline \multirow{3}{*}{ Years of training $n(\%)$} & $>3$ & $2(14.2)$ & $4(25.0)$ & \multirow{3}{*}{.703} & 0.099 \\
\hline & 4 to 12 & $6(42.9)$ & $7(43.8)$ & & 0.024 \\
\hline & More than 12 & $6(42.9)$ & $5(31.2)$ & & 0.03 \\
\hline \multirow{2}{*}{ Personal trainer $\mathrm{n}(\%)$} & Yes & $4(28.6)$ & $4(25)$ & \multirow{2}{*}{.825} & 0 \\
\hline & Not & $10(71.4)$ & $12(75)$ & & 0.028 \\
\hline \multirow{2}{*}{ Federated n (\%) } & Yes & $7(50.0)$ & $3(18.8)$ & \multirow{2}{*}{.070} & 0,113 \\
\hline & Not & $7(50.0)$ & $13(81.2)$ & & 0.090 \\
\hline \multirow{2}{*}{ Session duration n (\%) } & $41-60$ minutes & $7(50.0)$ & $8(50.0)$ & \multirow{2}{*}{1.000} & 0.020 \\
\hline & $>60$ minutes & $7(50.0)$ & $8(50.0)$ & & 0.020 \\
\hline \multicolumn{2}{|c|}{ Number of sessions per week. Mean (DT) } & $4.71(0.82)$ & $4.69(1.01)$ & .938 & 0.022 \\
\hline
\end{tabular}

DT (standard deviation).

Table 2. Dimensions of the POMS scale on the days with training and without training in athletes addicted and non-addicted to endurance running.

\begin{tabular}{|c|c|c|c|c|c|c|c|c|}
\hline & \multicolumn{2}{|c|}{ Addicted } & \multirow[b]{2}{*}{$p$-value } & \multirow[b]{2}{*}{ Cohen's d } & \multicolumn{2}{|c|}{ Non-addicted } & \multirow[b]{2}{*}{ p-value } & \multirow[b]{2}{*}{ Cohen's o } \\
\hline & $\begin{array}{l}\text { Training } \\
\text { Mean (DT) }\end{array}$ & $\begin{array}{c}\text { Break } \\
\text { Mean (DT) }\end{array}$ & & & $\begin{array}{l}\text { Training } \\
\text { Mean (DT) }\end{array}$ & $\begin{array}{c}\text { Break } \\
\text { Mean (DT) }\end{array}$ & & \\
\hline Borg (6-20) & $14.52(1.62)$ & NA & & & $13.67(1.75)$ & NA & & \\
\hline Tension & $0.66(0.79)$ & $1.38(1.06)$ & .011 & 0.770 & $0.38(0.33)$ & $0.59(0.36)$ * & .015 & 0.608 \\
\hline Depression & $0.16(0.22)$ & $0.73(0.94)$ & .022 & 0.835 & $0.04(0.06)$ & $0.04(0.06)$ * & .878 & 0 \\
\hline Vigor & $2.15(0.78)$ & $1.51(0.79)$ & .096 & 0.815 & $1.75(0.78)$ & $1.70(0.78)$ & .501 & 0,064 \\
\hline Fatigue & $1.24(0.74)$ & $0.62(0.53)$ & .006 & 0.963 & $0.95(0.51)$ & $0.23(0.19)$ * & .001 & 1.870 \\
\hline Anger & $0.19(0.28)$ & $0.92(0.95)$ & .002 & 1.042 & $0.11(0.14)$ & $0.19(0.25)$ * & .239 & 0.394 \\
\hline
\end{tabular}

* significant differences $(p<.05)$ with addicted group. DT (standard deviation). NA. Not applicable. 


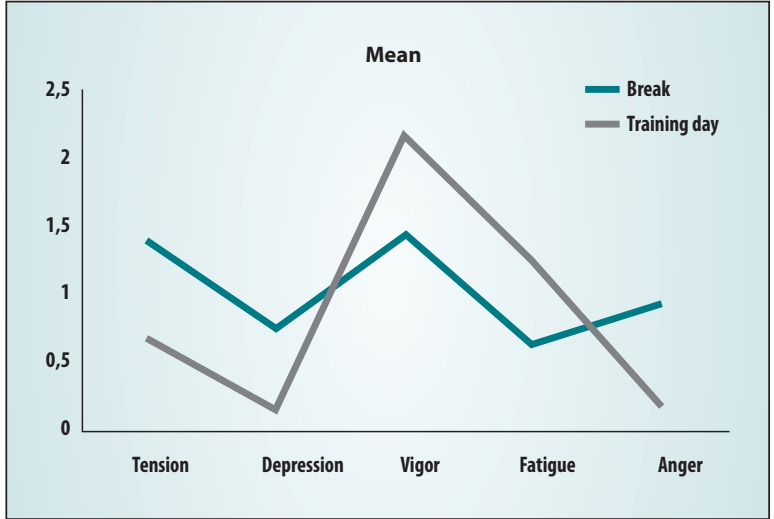

Figure 1. Mood Profile (POMS) on training and resting days in the addicted runners.

Figure 1 shows the mood profile of the addicted runners on training and resting days. It can be seen that the vigor is lower on resting days, a circumstance that is reversed in the group of non-addicted (Figure 2). Non-addicted athletes display an iceberg profile on training and resting days, but the addicted athletes only on training days.

Table 3 shows spearman correlation between the NAS scale and the POMS on training and resting days noted significant correlations $(\mathrm{p}<.05)$ between the NAS scale and tension, depression, fatigue and cholera on resting days, with no significant association being found with training days. Another correlation obtained in this study is the one found between the NAS scale and age $(r=-.516, p=.003)$.

Table 3. Spearman correlation between the NAS scale and the POMS on training and resting days.

\begin{tabular}{ccc}
\hline & Training & Break \\
\hline Tension & .088 & $.456 *$ \\
Depression & .096 & $.657 * *$ \\
Vigor & .307 & -.292 \\
Fatigue & .114 & $.373 *$ \\
Anger & .152 & $.416 *$ \\
\hline
\end{tabular}

$* p<.05, * * p<.01$

\section{Discussion}

The main finding of this study is to analyze the change in mood status in experienced veteran runners in both resting and training days, in relation to their level of dependence on endurance running. These changes were more important in the runners who had negative running addiction, with significant increases in depression, anger and tension in resting days; while fatigue is significantly reduced in both groups during resting. On resting days, the non-addicted group

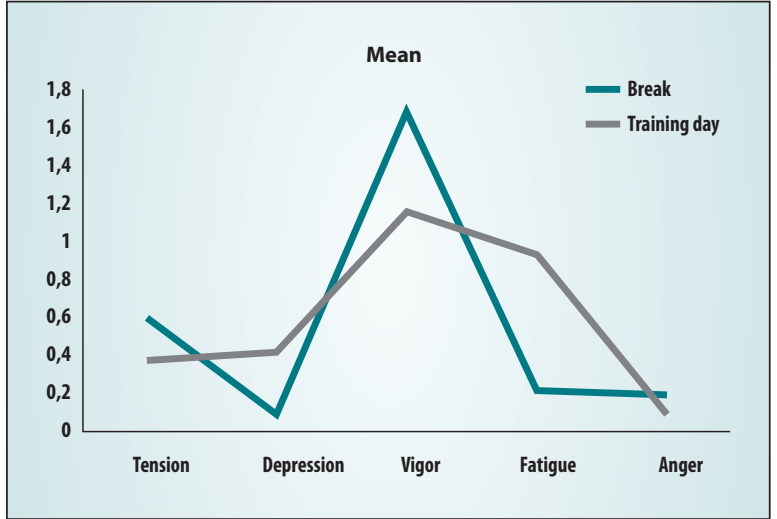

Figure 2. Mood Profile (POMS) on training and resting days in the nonaddicted runners.

obtained significantly lower values in the dimensions of tension, depression, fatigue and anger than the addicted group. The classic iceberg profile, typical for healthy athletes (Brandt et al., 2017; Morgan, \& Costill, 1997), is clearly seen in non-addicted athletes on resting and training days and in addicted athletes on training days; however, on resting days, addicted athletes show a $\mathrm{W}$ profile, where vigor shows values similar to tension and anger, above fatigue and depression. These data corroborate the hypothesis of how sport can influence mood status. The absence of the iceberg profile on resting days in addicted athletes could help to explain the dependence on endurance running through the POMS. These findings were especially relevant considering that the experimental procedure used a scheduled registry, known and controlled by the athlete, at medium term (one month), unlike previous training deprivation studies (Berczik et al., 2014; Egorov, \& Szabo, 2013; Landolfi, 2013; Márquez \& De la Vega, 2015; Parastatidou et al., 2014).

In a similar study, Aidman and Woolard (2003) using a controlled randomized trial, after deprivation of a scheduled training day, the exercise deprived group significantly reported withdrawal symptoms such as depression, reduced vigor and increased tension, anger, fatigue, and confusion (as measured by the POMS), as well as increased resting heart rate within $24 \mathrm{~h}$ after the missed training session. The control group that continued with the training showed no changes in mood or heart rate. But the most important of the contributions from the study by Aidman and Woolard (2003) was that the subjects with higher scores in addiction to physical exercise (Running Addiction Scale, RAS) experienced further changes in the mood status, which is in consonance with the findings reported by the current study. In addition, correlations between scores of RAS and magnitude of increases in tension, anger, confusion, the depression and the heart rate 
ranged between $r=.46-.58$. Results that also coincide with what was obtained in this study in which the NAS scale shows significant correlations with tension, depression, fatigue and anger that range from $r=.37$ to $r=.65$. Likewise, 2-week withdrawal of exercise provoked an increase of negative mood in athletes; the exercise addiction group showed an increase in depression, confusion, anger, fatigue and decreased vigor mood that improved post-exercise (Antunes et al., 2016).

These results suggest that the severity of withdrawal symptoms may be associated with the degree of negative running addiction. Therefore, the risk of addiction to exercise is positively correlated with the deterioration of mood and the time of participation in sports (Guszkowska, 2012). Likewise, Krivoschekov and Lushnikov (2017) noted that the athlete's functional state during exercise deprivation is an important predictor for exercise dependence. However, Modolo et al. (2011) using the NAS scale and the POMS, reported no significant differences in mood on a resting day in athletes with and without negative running addiction.

It has also been suggested that withdrawal symptoms only occur when physical activity cannot be performed at the time it was planned. If the subject has not planned to run in one or two days, the withdrawal syndrome does not appear (Berczik et al., 2012; Sachs, \& Pargman, 1985; Szabo et al., 2015). However, this study shows the opposite with endurance runners, especially those with negative addictions, showing alterations in their mood even on planned resting days.

Other studies with different athletes endorse the hypothesis of mood disorders when athletes are deprived of exercise, a circumstance possibly due to alterations in the Autonomous Nervous System (Bonet et al., 2017; Glass et al., 2004; Guerra et al, 2017; Hausenblas et al., 2008; Weinstein et al., 2007). In this regard, throughout the period of deprivation of physical exercise, the addicted group shows low levels of anandamide at all time-points evaluated and a modest increase in $\beta$-endorphin post-exercise (Antunes et al., 2016).

Therefore, physical exercises demonstrate the most obvious pattern of withdrawal-related symptoms mainly associated to mood disturbances (Fernandez et al., 2020). In this regard, mood can play a very important role in the development of dependence on physical exercise (Costa et al., 2013). According to Modolo et al. (2009) and Latorre et al. (2016) the type of sport influences the prevalence of dependence on physical exercise, thereby, individual sports practitioners present worse mood and quality of life than those of collective sports.

With a prevalence of $20.89 \%$, negative addiction can represent a major health problem in veteran athletes, affecting their quality of life (Salas et al., 2013). In any case, in this study and in line with Costa et al. (2013), age inversely correlates with addiction to physical exercise. Costa et al. (2013) also report that the reduction in dependence on physical exercise with age could be due to the parallel decrease in the level of physical activity. In the case of this study, this cause could not explain the inverse correlation of NAS with age since there are no significant differences in the number and duration of weekly training sessions in addicted and non-addicted athletes. Other aspects related to the type of motivations associated with endurance running, not analyzed in this study, could influence the inverse correlation between age and endurance running addiction.

As the most important limitation of this study, the authors would remark the lack of a specific analysis by sex. Moreover, with a small sample size, our findings must be interpreted with maximal caution. Future studies should provide more information in this regard.

This research has a relevant practical application, according to (Fernandez et al., 2020), the analysis of short-term abstinence may be of relevant importance as a clinical intervention for behavioral addictions. Moreover, these results should serve as a warning sign for amateur runners, coaches and physician of the presence of symptoms of physical exercise dependence.

\section{Conclusions}

Endurance runners with negative running addiction change their mood status on resting days, even when the rest is scheduled, increasing depression, anger and tension. The analysis of mood status alterations in athletes, and particularly in runners, could be an early indicator of the risk of negative addiction to physical exercise, in this case to endurance running. 


\section{REFERENCES}

Aidman, E.V., \& Woollard, S. (2003). The Influence of Self-Reported Exercise addiction on Acute Emotional and Physiological Responses to Brief Exercise Deprivation. Psychology of Sport and Exercise, 4(3), 225-36. doi.org/10.1016/S1469-0292(02)00003-1

Antunes, H. K. M., Leite, G. S. F., Lee, K. S., Barreto, A. T., Dos Santos, R. V. T., De Sá Souza, H., Tufik, S., \& de Mello, M. T. (2016). Exercise deprivation increases negative mood in exercise-addicted subjects and modifies their biochemical markers. Physiology \& behavior, 156, 182 190. Doi: 10.1016/j.physbeh.2016.01.028

Bamber, D. J., Cockerill, I. M., Rodgers, S., \& Carroll, D. (2000). “It's Exercise or Nothing": A Qualitative Analysis of Exercise Dependence. British Journal of Sports Medicine , 34(6), 423-430. Doi: 10.1136/ bjsm.34.6.423

Berczik, K., Szabó, A., Griffiths, M.D., Kurimay, T., Kun, B., Urbán, R., \& Demetrovics, Z. (2012). Exercise Addiction: Symptoms, Diagnosis, Epidemiology, and Etiology. Substance Use \& Misuse, 47, 403-17. https://doi.org/10.3109/10826084.2011.639120

Berczik, K., Griffiths, M., Szabo, A., Kurimay, T., Kokonyei, G., Urbán, R., \& Demetrovics, Z. (2014). Exercise addiction-the emergence of a new disorder. Australasian Epidemiologist, 21(2), 36.

Berlin, A. A., Kop, W. J. y Deuster, P. A. (2006). Depressive mood symptoms and fatigue after exercise withdrawal: the potential role of decreased fitness. Psychosomatic Medicine, 68, 224-30. https://doi. org/10.1097/01.psy.0000204628.73273.23

Bonet, J., Parrado, E., \& Capdevila, L. (2017). Efectos agudos del ejercicio físico sobre el estado de ánimo y la HRV / Acute Effects of Exercise on Mood And HRV. Revista Internacional de Medicina y Ciencias de la Actividad Física y el Deporte, 17(65), 85-100. https://doi.org/10.15366/ rimcafd2017.65.006

Borg, G. A. (1982). Psychophysical bases of perceived exertion. Medicine and

Science in Sports and Exercise, 14, 377-381. https://doi.org/10.1249/ 00005768-198205000-00012

Brandt, R., Bevilacqua, G. G., \& Andrade, A. (2017). Perceived sleep quality, mood states, and their relationship with performance among Brazilian elite athletes during a competitive period. Journal of strength and conditioning research, 31(4), 1033-1039. Doi: 10.1519/ JSC.0000000000001551

Castillo, M., Ortega, F. B., \& Ruiz, J. (2005). Mejora de la forma física como terapia antienvejecimiento. Medina Clínica, 124 (4),146-155. Doi: $10.1157 / 13071011$

Carmack, M. A., \& Martens, R. (1979). Measuring commitment to running: A survey of runner's attitudes and mental states. Journal of Sport Psychology, 1(1), 25-42. https://doi.org/10.1123/jsp.1.1.25

Cohen, J. (1988). Statistical power analysis for the behavioral sciences. Statistical Power Analysis for the Behavioral Sciences. https://doi. org $/ 10.1234 / 12345678$

Conboy, J. K. (1994). The Effects of Exercise Withdrawal On Mood States In Runners. Journal of Sport Behavior, 17 (3), 188-203.

Costa S., Hausenblas H., Oliva P., Cuzzocrea F., \& Larcan R. (2013). The role of age, gender, mood states and exercise frequency on exercise dependence. Journal of Behavioral Addictions, 2(4), 1-8. Doi: 10.1556/ JBA.2.2013.014

Egorov, A., \& Szabo, A. (2013). The exercise paradox: an interactional model for a clearer conceptualization of exercise addiction. Journal of Behavioral Addictions, 2(4), 199-208. Doi: 10.1556/JBA.2.2013.4.2

Fernandez, D. P., Kuss, D. J., \& Griffiths, M. D. (2020). Short-term abstinence effects across potential behavioral addictions: A systematic review. Clinical Psychology Review, 76, 101828. https://doi. org/10.1016/j.cpr.2020.101828

Fuentes, I., Balaguer, I., Meliá, J. L. y García-Merita, M. (1995). Forma abreviada del Perfil de Estado de Ánimo (POMS). En E. Cantón (Comp.). V Congreso Nacional de Psicología de la Actividad Física y el Deporte, pp. 19-26. Valencia: Universitat de València.

Garzón, M. J. C., Porcel, F. B. O., \& Ruiz, J.R. (2005). Mejora de la forma física como terapia antienvejecimiento. Medicina Clínica, 124(4), 146155. Doi: $10.1157 / 13071011$
Glass, J. M., Lyden, A. K., Petzke, F., Stein, P., Whalen G., Ambrose, K., ... Clauw, D. J. (2004). The effect of brief exercise cessation on pain, fatigue, and mood symptom development in healthy, fit individuals. Journal of Psychosomatic Research, 57(4), 391- 398. Doi: 10.1016/j. jpsychores.2004.04.002

Glasser, W. (1976). Positive addiction. New York: Harper and Row, Publishers, Inc.

Guerra, J. R., Gutiérrez, M., Zavala, M., Singre, J., Goosdenovich, D., \& Romero, E. (2017). Relación entre ansiedad y ejercicio físico. Rev Cubana Invest Bioméd, 36(2), 169-177.

Guszkowska, M. (2012). Exercise dependence-symptoms and mechanisms. Psychiatria Polska, 46 (5), 845-56.

Hailey, B. J., \& Bailey, L. A. (1982). Negative addiction in runners: a quantitative approach. Journal of Sport Behaviour, 5, 150-1544.

Hambleton, R. K. (1996). Adapting tests for use in multiple languages and cultures: error sources, possible solutions and practical guidelines. In J. Muñiz (Ed.), Psicometría (pp. 207-238). Madrid: Universitas.

Hausenblas, H. A., Gauvin, L., Downs, D. S., \& Duley, A. R. (2008). Effects of abstinence from habitual involvement in regular exercise on feeling states: An ecological momentary assessment study. British Journal of Health Psychology, 13 (2), 237-255. Doi: 10.1348/135910707X180378

Hausenblas, H. A., \& Symons Downs, D. (2002). Exercise dependence: A systematic review. Psychology of Sport and Exercise, 3, 89-123. https:// doi.org/10.1016/S1469-0292(00)00015-7

Krivoschekov, S. G., \& Lushnikov, O. N. (2017). The functional state of athletes addicted to exercises during exercise deprivation. Human Physiology, 43(6), 678-685. Doi: 10.4172/2157-7595.1000288

Landolfi, E. (2013). Exercise addiction. Sports Med, 43, 111-119. https:// doi.org/10.1007/s40279-012-0013-x

Latorre, P. A., Jiménez, A., Párraga, J., \& García, F. (2016). Dependencia al ejercicio físico e insatisfacción corporal en diferentes deportes de resistencia y su relación con la motivación al deporte. Revista de psicología del deporte, 25(1), 113-120.

Márquez, S., \& De la Vega, R. (2015). La adicción al ejercicio: un trastorno emergente de la conducta. Nutrición Hospitalaria, 31, 2384-2391. http://dx.doi.org/10.3305/nh.2015.31.6.8934

McNair, D. M., Lorr, M., \& Droppleman, L. F. (1971). Manual for the Profile of Mood

States. San Diego, CA: Educational and Industrial Testing Service.

Meeusen, R., Watson, P., Hasegawa, H., Roelands, B., \& Piacentini, M. F. (2006). Central Fatigue. The serotonin hypothesis and beyond. Sports Medicine, 36 (10), 881-909. https://doi.org/10.2165/00007256200636100-00006

Modolo, V. B., Antunes , H. K. M., Gimenez, P. R. B., Santiago, M. L. M., Tufik, S., \& Mello M. T. (2011). Negative addiction to exercise: are there differences between genders?. Clinics, 66 (2), 255-260. Doi: 10.1590/ S1807-59322011000200013

Modolo, V. B., Mello, M.T., Gimenez, P. R. B., Tufik, S., \& Antunes, H. K. M. (2009). Dependência de exercício físico: humor, qualidade de vida em atletas amadores e profissionais. Revista Brasileira de Medicina do Esporte, 15 (5), 355-359. https://doi.org/10.1590/S151786922009000600007

Mondin, G. W., Morgan, W. P., Piering, P. N., Stegner, A. J., Stotesbery, C. L., Trine, M. R. \& Wu, M. Y. (1996). Psychological consequences of exercise deprivation in habitual exercisers. Medicine and Science in Sports and Exercise, 28 (9), 1199-1203. https://doi.org/10.1097/00005768199605001-00173

Morgan, W. P. (1979). Negative addiction in runners. The Physician and Sports Medicine, 7, 57-77. Doi: 10.1080/00913847.1979.11948436

Morgan, W. P. (1980). Test of champions: The iceberg profile. Psychology Today, 14, 39-108.

Morgan, W. P., \& Costill, D. L. (1996). Selected psychological characteristics and health behaviors of aging marathon runners: a longitudinal study. International journal of sports medicine, 17(04), 305-312. Doi: 10.1055/ s-2007-972852

Nogueira, A., Salguero, A. \& Márquez, S. (2017). Adicción a correr: una revisión desde sus inicios hasta la actualidad. Revista de Psicología 
Aplicada al Deporte y el Ejercicio Físico, 2(1), 1-22. https://doi. org/10.5093/rpadef2017a1

Parastatidou, I., Doganis, G., Theodorakis, Y., \& Vlachopoulos, S. (2014). The mediating role of passion in the relationship of exercise motivational regulations with exercise dependence symptoms. International Journal of Mental Health and Addiction, 12, 406-419. https://doi.org/10.1007/s11469-013-9466-x

Reynaga-Estrada, P., Arevalo Vazquez, E. I., Verdesoto Galeas, A. M. Jimenez Ortega, I. M., Preciado Serrano, M. D. L., \& Morales Acosta, J. J. (2016). Psychological benefits of physical activity in an educational center work. Retos-nuevas tendencias en educacion fisica deporte $y$ recreacion, 30, 203-206.

Rowley, A. J., Landers, D. M., Kyllo, L. B., \& Etnier, J. L. (1995). Does the Iceberg Profile discriminate between successful and less successful athletes? A meta-analysis. Journal of Sport and Exercise Psychology, 17 (2), 185-199. Doi: 10.1123/jsep.17.2.185

Ruiz-Juan, F., Zarauz, A., \& Flores-Allende, G. (2016). Dependence to training and competition in route runners. Cultura_Ciencia_Deporte, 11(32), 14. Doi: 10.12800/ccd.v11i32.714
Salas-Sánchez J., Latorre-Roman P. A., \& Soto-Hermoso V. M. (2013). Negative dependence to the career of resistance and corporal dimorphism in veteran athletes. Medicina dello Sport, 66(3), 375-87

Sachs, M., \& Pargman, D. (1985). Running addiction. En M. Sachs y G. Buffone (eds.) Running as Therapy (pp.231-255). Lincoln (Nebraska): University of Nebraska.

Szabo, A. (2000). Physical activity as a source of psychological dysfunction. In SJH Biddle, KR Fox, SH Boutcher, (Eds) Physical activity and psychological well-being (pp 130-153). London: Routledge.

Szabo, A., Griffiths, M.D., De La Vega Marcos, R., Mervó, B., \& Demetrovics, Z. (2015). Methodological and conceptual limitations in exercise addiction research. Yale Journal of Biology and Medicine, 88(3), 303-308.

Wilhelm, M. (2014). Atrial fibrillation in endurance athletes. European Journal of Preventive Cardiology, 21, 1040-1048. Doi: $10.1177 / 2047487313476414$

Weinstein, A.A., Deuster, P.A., \& Kop, W.J. (2007). Heart rate variability as a predictor of negative mood symptoms induced by exercise withdrawal. Medicine and Science in Sports and Exercise, 39(4), 735741. Doi: $10.1249 / \mathrm{mss} .0 \mathrm{~b} 013 \mathrm{e} 31802 \mathrm{f590c}$ 